\title{
Tanatopolítica, ser nacional y guerra preventiva en la Argentina (1976-1983), a través de las revistas Evita Montonera, Estrella Federal, Extra, Carta Política y otros documentos*
}

\author{
Cristina Micieli \\ Myriam Pelazas \\ Equipo de investigación (UBACyT 2013-2015)*
}

\section{Resumen}

Este artículo ofrece las conclusiones preliminares de nuestra investigación "'Ser Nacional': del 'ni vencederos, ni vencidos' a 'ni muertos, ni vivos, desaparecidos'. Tanatopolítica e identidad en Argentina (1976-1983)", (UBACyT (2013-2015).

La naturaleza del Terrorismo de Estado argentino se materializa en la "reproducción ideológica" del "Ser Nacional" y en el exterminio del "subversivo", en tanto enemigo de los valores occidentales y cristianos, y cuyo alcance fue tan vasto como imprevisible. Para el "Proceso" los subversivos quedaban prácticamente afuera de la categoría de "persona", como si se tratara de seres distintos a ese argentino "puro" que debía ser "protegido". Se niegan vidas para proteger vidas...: ésta es la paradoja de la "tanatopolítica". La inmunidad preserva la comunidad, afirma Esposito. Cualquier "contagio" del cuerpo social habrá de conjurarse con la guerra preventiva. Dicha lógica se arroga la facultad de interpretar los miedos ante lo "extraño",

* Artículo recibido el 29 de mayo de 2014. Aceptado el 20 de noviembre de 2014.

* La investigación "Ser Nacional: del 'ni vencedores, ni vencidos' a 'ni muertos, ni vivos, desaparecidos'. Tanatopolítica e identidad en Argentina (1976-1983)" (UBACyT 2013-2015 de la Facultad de Ciencias Sociales de la UBA), está dirigida por Cristina Micieli y co-dirigida por Myriam Pelazas. El equipo de investigación está formado por Graciela Colombani, Pablo Dipierri, María E. Mira, Gustavo C. Picotti y Gustavo Salmún Feijoó. Correo electrónico: cmicieli@educ.ar 
así como la necesidad de protección ante peligros reales o aparentes.

\section{Palabras clave}

Dictadura - Tanatopolítica - Identidad.

\section{Abstract}

This issue introduces preliminary conclusions of our research "'Being National': from 'not defeaters nor defeated' to 'not dead nor alive, disappeared'. Tanato-politics and identity in Argentina (1976-1983)", (UBACyT 2013-2015).

The nature of Argentine State Terrorism is materialized in the "ideological reproduction" of Being National and in the extermination of the "subversive", enemy of Christian and occidental values, and whose scope was as vast as unforeseeable. For the "Process" the subversive people were almost out of category of "people" as if they were different beings than those pure Argentine people that should be "protected". Lives are denied in order to protect other lives...: this is the "tanato-politics" paradox. Immunity preserves community, states Espósito. Any "infection" of the social body should plot together with the preventive war. This logic assumes the faculty of interpreting the fears before the "peculiar thing", as well as the need of protection before real or apparent dangers.

\section{Keywords}

Dictatorship - Tanato-politics - Identity.

\section{Introducción}

El objeto del presente artículo es anticipar algunas conclusiones de la investigación "Ser Nacional: del 'ni vencedores ni vencidos' a 'ni muertos, ni vivos, desaparecidos'. Tanatopolítica e identidad en Argentina (1976-1983)", que es continuación de la investigación "Dar la vida/quitar la vida: el peronismo en los 70 a través de las revistas El Descamisado y El Caudillo" (1973-1976), llevada a cabo en el bienio 2011-2013. 
En ellas hemos seguido el derrotero de la Juventud Peronista, y de su organización armada, Montoneros, a través de sus publicaciones: El Descamisado, Evita Montonera y Estrella Federal, entre otras.

Asimismo, utilizamos como marco teórico la biopolítica, en su vertiente italiana principalmente, sin por ello dejar de tener en cuenta los ricos aportes de Foucault teórico de tal concepción en tanto intervención del poder en la vida humana- respecto del nacionalsocialismo.

Conceptos como estado de excepción, nuda vida, homo sacer, tanatopolítica, guerra preventiva, comunidad, inmunidad, entre otros, son de gran utilidad para analizar ambos períodos (1973-1976; 1976-1983) ya que pudimos constatar que a la consigna de la Revista El Caudillo a partir de febrero de 1974, "El mejor enemigo es el enemigo muerto", que se traducirá en las ejecuciones llevadas a cabo por la Triple A, de la que era su órgano de prensa, se sumará el decreto firmado por Isabel Perón en 1975, que disponía en un artículo la aniquilación de la guerrilla en la provincia de Tucumán. Tal decreto -extendido a todo el país por Luder, en tiempos de licencia de la presidenta-, junto con los homicidios de la Triple A, fueron anticipaciones de lo que sucedería a partir de 1976.

En efecto, bajo parte del tercer período de gobierno de Perón, y a lo largo de todo el mandato de Isabel Martínez, la violencia y los asesinatos perpetrados por la Triple A estuvieron dirigidos a socavar la identidad de un grupo de jóvenes peronistas -la JP y sus ramas, sobre todo, pero también organizaciones como el ERP, entre otras. La Triple A fue el embrión de lo que poco después sería el terrorismo de Estado en la Argentina, inserto en la "comunidad" represiva del Plan Cóndor (Micieli, C. et al., 2012).

A partir del 24 de marzo de 1976, la política de desapariciones de la AAA tomó el carácter de modalidad represiva estatal, abriendo una nueva época en la lucha contrainsurgente. En pocos meses las FF.AA. destruyen casi totalmente al ERP y a las regionales de Montoneros que operaban en Tucumán y en Córdoba. (Calveiro, 2013, p. 107)

La dictadura dará los golpes finales sobre fuerzas política y militarmente diezmadas, y a través del terrorismo de Estado, extenderá con inusitada crueldad una represión de redisciplinamiento social destinada a desterrar los elementos disolventes -a su entender- que habían emergido desde la década del 60 en un clima de radicalización política e innovación cultural. El balance final arrojó como resultado una de las derrotas más catastróficas de la izquierda argentina en sus cien años de existencia y el drama más severo de la historia del país del siglo pasado.

El llamado Proceso no puede entenderse como una simple continuación, una repetición exagerada de prácticas antes vigentes. Representó, por el contrario, una nueva configuración del poder, imprescindible para la institucionalización que le siguió. Ni más de lo mismo ni un monstruo que engendró incompresiblemente la sociedad. Un 
hijo legítimo pero que muestra una cara terriblemente desagradable, que exhibe sin pudor las vergüenzas de la familia, ocultando parte de su ser más íntimo. Poder desaparecedor que se gesta a lo largo del tiempo, que se esconde detrás del pretendido 'exceso', para a su vez desaparecerse una y otra vez en los pliegues de la historia. (Calveiro, 2013, p. 108)

El papel y las prácticas que asumieron las FF.AA. en 1976 fueron la culminación de un largo proceso de usurpación y sustitución del lugar del Estado, con el consentimiento de amplios sectores sociales y políticos. Entre 1930 y 1976, la cercanía con el poder, la pugna por él y la representación de diversos proyectos de los sectores dominantes les fueron dando a las FF.AA. un peso político propio. Esto condujo a lo que Calveiro denomina "proceso de militarización del Estado" (Calveiro, 2013, p. 56).

Después de 1976 el socavamiento y la aniquilación tienen un radio de alcance indudablemente mayor. En efecto, luego del 24 de marzo las acciones violentas son necesarias para poder dominar a las personas. Tales acciones llevan a cabo una masificación donde se deja de reconocer a los participantes en sí mismos. En esas acciones se genera una incapacidad de pensamiento, que se refleja en la detención de la reflexividad y la imposibilidad de desarrollar la capacidad de juicio, suspendiendo el diálogo, la deliberación y la libertad. El golpe del 76 hizo "superfluos" a los hombres, los convirtió en sobrantes, como afirma Agamben, lo cual significa su cancelación como humanos. Se los trató como mera vida -nuda vida-(Agamben, 2003, p. 3).

El accionar del Estado terrorista rompe con las categorías tradicionalmente aplicadas a las prácticas gubernamentales. Podría suponerse que existe alguna proximidad con los Estados dirigistas como el nacionalsocialismo o el fascismo, pero en estos casos que pueden coincidir con aquellos en haber cometido crímenes de lesa humanidad sistemática y masivamente- las condiciones de gubernamentalidad son netamente diferenciables.

El Estado nazi, como afirma Michel Foucault (1996, pp. 206-207), es la convergencia de un biopoder generalizado y una dictadura absoluta, retransmitido en todo el cuerpo social. El Estado es, en consecuencia, "absolutamente racista y absolutamente homicida". Pero estas características propias del nazismo son resignificadas en el contexto del terrorismo de Estado de 1976 en Argentina. No obstante, tanto el nazismo como el terrorismo de Estado argentino poseen un trasfondo biológico e ideológico, aunque cada uno de los dos regímenes expresen estas particularidades de modos distintos. En el caso del nazismo, la visibilidad de la manipulación biológica enmascaró la ideología propia del Nacionalsocialismo. Por su parte, en el contexto del "Proceso de Reorganización Nacional", las particularidades de funcionamiento del régimen Nacionalsocialista adoptan una configuración inversa. Si bien la polarización "capitalismo-comunismo" está a la orden del día en ambos casos, en el caso argentino se sumará la disputa entre el bloque soviético y el occidental capitalista durante la post Segunda Guerra Mundial -la llamada "guerra fría". La Doctrina de Seguridad Nacional 
vigente acentuará las banderas ideológicas de lucha contra el marxismo encarnado en la "subversión apátrida", mientras que todo el aparato biopolítico implementado como política de Estado fue exitosamente ocultado. En este sentido, la construcción del concepto de "Ser Nacional", como rescate y exaltación de valores tradicionales como la familia, la patria y la Iglesia, junto a la censura y el señalamiento de lo peligroso representado por los "subversivos", eclipsaron la instrumentación de las técnicas del biopoder (el secuestro, la desaparición, la tortura clandestina, el asesinato y el ocultamiento del cadáver).

Tanto el Nacionalsocialismo como la Junta Militar de 1976 requerían de la identificación de "un enemigo" del cual diferenciarse para construir su identidad política. El cuerpo del Otro, de la subversión, fue dotado de características despreciables con el objeto de ubicarlo fuera de la categoría de "persona". El país fue asimilado a un cuerpo biológico, que había sido "infectado" por la subversión. Era inminente llevar a cabo una operación de "cirugía mayor".

En el 76 la dictadura construyó una propuesta que hacía énfasis en la voluntad de una transformación drástica del presente y buscaba instalar un corte fundacional, el comienzo de un nuevo ciclo histórico que borraría, aniquilándolo, el pasado. No obstante, las FF.AA. habían sido parte activa de la larga crisis política y estaban impregnadas, por lo tanto, de los mismos factores de desorden y facciosidad que dominaban algunos espacios colectivos. En estas condiciones pudieron encarnar la reserva del orden y la autoridad, según una tradición que se remontaba, en un "linaje fantástico", como bien dice Hugo Vezzetti (2008, p. 35), a Roca y a los mitos sanmartinianos. Esto muestra el peso de la "construcción imaginaria" de la escena política y social.

En este punto, la disputa ideológica con la oposición, incluso con la guerrilla, era una disputa sobre el significado mismo de la idea de Nación. Frente a lo que se concebía como una agresión externa, los nuevos "cruzados" venían a sostener a sangre y fuego que el "verdadero nacionalismo" era el de las FF.AA. y no el de un falso discurso de "liberación nacional" que encubría el designio de someterse al poder comunista mundial.

Si bien la llamada "defensa del ser nacional" formaba parte de una visión que repetía los clichés del fascismo criollo contra la democracia y el peligro del marxismo, ella le permitió al "Proceso" el suficiente consenso como para "purificar" la Nación exterminando el peligro que representaban estos Otros llamados subversión.

\section{El "estado de excepción"}

Siguiendo la indagación genealógica de Agamben, el moderno estado de excepción -que echa sus raíces en el iustitium romano- es un espacio vacío de derecho. En este marco, la organización jurídica del régimen militar instalado en 1976 acarrea una serie de enormes modificaciones del estado de derecho, que ya venía implementándose 
desde gobiernos anteriores: en el vértice de la pirámide se ubica el "Acta" y el "Estatuto" y otras disposiciones originadas en el gobierno de facto. En este punto, vemos con claridad la génesis de un nuevo derecho.

Remitiéndonos a Benjamin, este autor advierte que el derecho no es la abolición del antiguo ritual del sacrifico de una víctima, sino su transposición moderna. La violencia, en lugar de ser eliminada, es asumida por el poder. Esposito, siguiendo la argumentación de Benjamin, observa que la "dialéctica inmunitaria" que se determina de este modo se puede resumir en tres pasos conectados entre sí. Al comienzo hay siempre un acto violento -una guerra o una usurpación como en el caso que nos ocupa- que funda un orden jurídico. Después, una vez fundado, el derecho tiende a excluir cualquier otra violencia externa a sus procedimientos. Pero solo puede hacerlo violentamente, haciendo uso de la violencia que condena. Así es como Benjamin puede concluir que "el derecho no es otra cosa que la violencia a la violencia por el control de violencia" (Esposito, 2010, p. 115).

El problema crucial relacionado con la suspensión del estado de derecho es el de los actos cometidos durante el iustitium, cuya naturaleza "parece escapar a toda definición jurídica. En cuanto no son ni transgresivos, ni ejecutivos, ni legislativos, parecen situarse con respecto al derecho en un no-lugar". A este no-lugar responde la fuerza-de-ley, que encarna una contradicción en sus propios términos, ya que según Agamben, 2005, p. 79, este sintagma no se refiere a la ley como en la doctrina moderna o la antigua, sino a aquellos decretos -que poseen precisamente fuerza de ley- que el poder ejecutivo está autorizado a emanar en algunos casos, y, particularmente, en el estado de excepción.

Ideólogos de la dictadura como Mariano Grondona justifican, desde la Revista Carta Política, el golpe militar de 1976, estableciendo la ecuación dictadura militar argentina = dictadura romana, con lo cual se refería a que cuando llegaba la noticia de una situación que ponía en peligro a la República, el Senado romano daba lugar a la proclamación de un iustitium, que significa literalmente la interrupción o suspensión del derecho. Esta institución tenía en su base un decreto que declaraba el tumultus, que era la situación de emergencia que advenía en Roma luego de una guerra externa, una insurrección o una guerra civil. Sin embargo, lo que el periodista olvida es que el dictador romano también era responsable de sus actos ante la ley por más que los poderes que se le daban fueran totales; una vez expirado el período de la dictadura, el Senado le exigía la justificación de todas las medidas adoptadas durante su gobierno. Asimismo, en el pensamiento político contemporáneo, la idea de dictadura no aparece como "dignidad republicana" sino como una institución que la distancia del concepto tradicional en la antigua Roma.

Esta Revista es otra de las fuentes que estamos analizando en esta investigación, junto a la revista Extra, de Bernardo Neustadt, ya que desde sus páginas se intentó buscar consenso social y darle de ese modo legitimidad al golpe. 
En el caso de Carta Política, la justificación del golpe se asienta en bases históricofilosóficas, mientras que en Extra, Neustadt busca sus causas en el ocaso del populismo y en la desintegración de la Nación tras los gobiernos de estas características.

Así, por ejemplo, en un editorial titulado "Las monarquías fundantes" ( $N^{\circ} 31$ de mayo de 1976), Grondona se pregunta si se puede fundar la democracia desde la autocracia. El autor pretende demostrar que esos términos antitéticos están unidos y compenetrados por lo que se desprende de sus conceptos. Históricamente, se sostiene, la democracia es hija de la monarquía, es decir, la autocracia. "Durante siglos, las autocracias hereditarias impusieron al pueblo el hábito de la obediencia a la ley", y lo prepararon para la democracia. En consecuencia, el régimen militar de 1976 sería el progenitor de la futura democracia. Así, el golpe ha dado nacimiento a una etapa de "fundación monárquica" prerrequisito para el advenimiento de la democracia, pues solo a través de este itinerario "desgraciado" y colmado de sinsabores "habremos aprendido a obedecer la ley", solo así "mereceremos hacerla". Sin autodisciplina no puede haber democracia. Pero la democracia que es fruto de la autodisciplina no puede sembrarla" (mayo de 1976).

En este sentido, el "Proceso de Reorganización Nacional" anunciaba desde la desmesura de esa denominación que no le bastaba intervenir sobre el Estado y las instituciones, sino que la Nación misma sería objeto de reconstrucción y regeneración social y política. Su irrupción se sustentaba en el fantasma del caos y el despedazamiento del cuerpo social, aunque en 1976 las organizaciones guerrilleras estaban prácticamente derrotadas, por lo tanto no se confrontaría con un enemigo armado, sino con una figura amplia del "mal", la "subversión". En ese marco, el golpe se justificaba en la constatación de las crisis por las que atravesó el país, en particular por el "vacío de poder" que generó el último gobierno peronista (Quiroga, 2004). "Todo aquello conducía a la 'disolución de la Nación' y a la anarquía'", tal como lo establece su "Proclama".

Utilizando antinomias irreconciliables, Videla expresa en el Mensaje del 24 de mayo de 1976 que hasta el 24 de marzo "estaban comprometidos el orgullo nacional y la propia existencia como Nación soberana...". A la Verdad se le oponía el Engaño, a la Razón el Mito, al Interés General el Personalismo y sus apetencias facciosas. Escepticismo, abatimiento, pérdida de la esperanza, corrupción, incapacidad, violencia, desánimo e incredulidad envolvían la atmósfera del "hombre común": solo "algunos elegidos" podían develar la verdad tras la maraña de mentiras y sinsabores. Los Jefes de las Fuerzas Armadas acudieron una vez más al llamado de la auténtica argentinidad para reencauzar una juventud desconcertada y descarriada. La inseguridad, la indisciplina, la desorganización, la improvisación, la lenidad, la deshonestidad, el desorden, el descreimiento, el desgobierno, la degradación, el trastrocamiento de valores, la injusticia y la digitación compulsiva, verían su punto final al cabo de la construcción de la nueva Argentina que impulsará las "mejores tradiciones". 
Videla ya había adelantado el proyecto en el mensaje pronunciado el 17 de abril de 1976:

...vamos hacia un cambio en profundidad. Cambio en lo moral...Cambio en lo político...Cambio en lo económico...Cambio en lo social...Un cambio en profundidad que abarque a las personas y a las cosas, a los hábitos y a las instituciones, presupone la necesidad de un esfuerzo prolongado...

Se trataba de superar la "crisis de identidad que se manifiesta en un permanente cuestionamiento de los valores tradicionales de nuestra cultura, y asume, en muchos casos, las concepciones nihilistas de la subversión antinacional...". El intento de cambio cultural está a las puertas...

Por otra parte, en Evita Montonera (febrero-marzo de 1977, p. 15) se lleva a cabo un balance de lo actuado por los golpistas. Allí se dice que el derrocamiento de Isabel fue la única alternativa que tuvieron las clases dominantes para enfrentar la situación y cambiar la relación de fuerzas entre ellas y el pueblo junto a sus organizaciones. Una vez más, las Fuerzas Armadas asumen el papel de Partido Político-Militar de la oligarquía y los monopolios. "Otra dictadura que viene a 'arreglar' (léase 'arrasar' al país). Los milicos, desde Mitre a la fecha, nunca se equivocaron (salvo excepciones casi individuales que ellos mismo aplastaron), como el General Perón...".

Evita Montonera, lo mismo que sus antecesoras -El Descamisado, El Peronista y La Causa Peronista- sostiene una idea de Nación que reivindica la lucha de los caudillos federales contra la política porteña y su defensa de los intereses oligárquicos sintetizados en el modelo agro-exportador y en la alianza estratégica con Inglaterra.

"La dictadura: tiene su origen en la crisis económica del capitalismo monopólico; su concreción es el cierre de un ciclo que se inicia en 1973; constituye un salto en el proceso de acumulación de poder enemigo; la ofensiva del enemigo se desarrolla sobre los ejes clásicos con que la oligarquía y los monopolios enfrentaron siempre estas crisis; la ofensiva militar sobre el espacio popular organizado es a fondo; pierde casi totalmente el espacio político que generaba la expectativa de los sectores medios...".

Hemos identificado que en plena dictadura militar, la organización insiste con la consigna "Resistencia obrera, resistencia montonera", y así lo editorializa en varios números de la publicación (Evita Montonera (abril-mayo de 1976, p. 13); Evita Montonera (febrero de 1977, p. 15).

En mayo de 1977 aparece el primer número de Estrella Federal, "órgano oficial del Ejército Montonero", cuyo título de tapa manifiesta que "Las armas del Ejército Montonero atacan la dictadura de Videla". 
A partir del golpe, Montoneros siguió con el accionar militar a pesar de sus derrotas, la desmovilización de las bases y su desconexión con estas. No hubo un momento de reflexión, replanteo, cuestionamiento.

\section{El biopoder}

Como dijimos en la introducción a este trabajo, el primer plano que adquirió "la lucha por la defensa del Ser Nacional" como sinónimo de "realización de la misión de la familia" o "preservación y consolidación de los valores occidentales y cristianos" contra los antivalores encarnados en los subversivos, eclipsó la instrumentación de las técnicas del biopoder, entre las cuales la desaparición de personas ocupa el lugar más relevante.

En efecto, "la desaparición es lo que vuelve al opositor un homo sacer, es decir personas que pueden ser asesinadas impunemente" (Agamben, 2003, p. 35). El llamado homo sacer es una figura jurídica del derecho romano que se caracteriza por su exposición a la muerte.

En todas las épocas y en todas las culturas se pueden rastrear vestigios de esta figura, pero con el surgimiento del biopoder como atributo estatal específico, se implementaron medidas que posibilitaron y promovieron exterminios. En la Argentina naciente, por ejemplo, el indio se constituyó en homo sacer por excelencia. Roca utilizó ampliamente esa especie de licencia para matar a los marcados por el poder. Las personas masacradas por sus tropas, es decir los indios, no eran, desde el punto de vista legal, más que un puñado de vidas. Algo similar ocurrió con la subcultura gaucha. Como vemos, hay antecedentes de la figura del homo sacer en nuestro país (Díaz, 2010). Durante la última dictadura cívico-militar en Argentina, el supuesto terrorista también fue considerado homo sacer.

La celebración del Centenario de la "Campaña al Desierto" en 1979 ofreció a la dictadura la posibilidad de exhibir las equivalencias con las promesas de un nuevo comienzo que también se fundaba en la contundencia de las armas contra un enemigo irrecuperable. Esa "igualación imaginaria" de los salvajes aniquilados por las fuerzas de Roca con los subversivos que amenazaban la esencia de la Nación fundaba la "proyección épica" de un nuevo origen. "Bajo el término subversión se alucinaba, señala Vezzetti (2008, p. 71), una vasta conspiración que igualaba a las acciones de la guerrilla con las expresiones más variadas del cuestionamiento y la movilización política, sindical o estudiantil".

\section{El campo}

El 24 de marzo significa la era de la planificación racional y moderna de la muerte, pero se trataba de una muerte secreta, subterránea, silenciosa, furtiva. Fuera de la estructura de mandos, la dictadura creó Grupos de Tareas y Centros Clandestinos de Detención. La ingeniería represiva tuvo la particularidad de funcionar como una maquinaria de engranajes, cuya segmentación dividía el trabajo diluyendo las 
responsabilidades, dotando a los procedimientos de una apariencia burocrática consistente en la ejecución de tareas rutinarias y mecánicas, a la vez que lograba involucrar a gran parte de la corporación militar. En efecto, las características del poder político del "Proceso" se evidencian en una de sus criaturas, quizá la más oculta, una creación periférica y medular al mismo tiempo: el campo de concentración. Refiriéndose al campo de concentración nazi, Esposito (2004) afirma que el nazismo extendió la ley hasta incluir en ella aquello que la excede manifiestamente. El campo no es el lugar de la ley, pero tampoco es el de la mera arbitrariedad. Es más bien el espacio donde lo arbitrario se torna legal y la ley arbitraria.

Asimismo, el campo de concentración está destinado a encerrar a autores de crímenes aún no cometidos, y por consiguiente, no juzgables sobre la base de los ordenamientos vigentes, configurándose como el lugar para "una detención preventiva".

La secuencia de los "operativos" llevados adelante por los Grupos de Tareas seguía un modus operandi relativamente estable, de ahí que habría una coincidencia con la afirmación de Esposito: el "campo de concentración" no es el lugar de la ley pero tampoco es el de la mera arbitrariedad. Para Agamben, los campos de concentración nacen del estado de excepción ya que allí se da una indefinición entre hecho y derecho. El campo de concentración es el espacio que se abre cuando el estado de excepción empieza a convertirse en regla. Se establece una tendencia a la habitualidad y se confunde excepción con normalidad.

Los habitantes del campo, al haber sido despojados de cualquier condición política y reducidos íntegramente a una vida desnuda -nuda vida- colocan al campo en un espacio biopolítico de magnitud ya que el poder no encuentra contraposición más allá de la nuda vida, sin mediación alguna. El campo es el paradigma biopolítico por excelencia, donde el homo sacer se confunde virtualmente con el ciudadano. Hannah Arendt refiriéndose a los campos de concentración nazi o "fábricas de la muerte", como los llama, afirma que los hombres fueron allí reducidos al mínimo común denominador de la vida orgánica, y rebajados al abismo más oscuro y sombrío de la originaria igualdad. En fin, fueron tratados como ganado, como material, como cosas, como meros seres vivientes. Vistos de esta manera, "los campos de exterminio son lugares en los que la reducción del hombre a su mera y nuda vida ha encontrado una realización consecuente" (Arendt, 1989, p. 50). Al degradarse la existencia a mera materialidad, puede ejercerse sobre ella el peor de los tormentos y la muerte brutal.

El 23 de agosto de 1976, el general Roberto Eduardo Viola elaboró el plan de operaciones del golpe llamado "Instrucción de lucha contra elementos subversivos". Conocido como Documento Reservado del Ejército Argentino, el plan consta de 2 partes. En la Primera Parte, se enfatizan las operaciones de "contra subversión" que debían tener "un carácter eminentemente ofensivo", dándose prioridad a los conceptos de "persecución y aniquilamiento". Por "las características especiales que impone la lucha 
contra los elementos subversivos, se impone la necesidad de emplear procedimientos $y$ técnicas particulares de combate" ${ }^{1}$ Desde el comienzo, y aun antes del orden autoritario, los enemigos fueron identificados como subversivos, populistas, estatistas y corruptos.

\section{Un nuevo modelo de acumulación}

La economía de la dictadura fue indudablemente la otra cara del genocidio perpetrado por los militares, ya que los niveles de exclusión social se elevaron de manera nunca antes concebida en el país.

En este sentido, Videla reveló en Disposición Final (2012) que el golpe de Estado de 1976 no se debió tanto a la lucha contra las guerrillas sino a una razón más abarcadora: "Nuestro objetivo era disciplinar a una sociedad anarquizada, volverla a sus principios, a sus cauces naturales. Con respecto al peronismo, salir de una visión populista, demagógica, que impregnaba a varios sectores; con relación a la economía, ir a una economía de mercado, liberal. Un nuevo modelo, un cambio bastante radical; a la sociedad había que disciplinarla para que fuera más eficiente. Queríamos también disciplinar al sindicalismo y al capitalismo prebendario".

Las categorías empleadas por Bernardo Neustadt en su revista Extra para legitimar el "Plan Martínez de Hoz" tienen un carácter eminentemente biopolítico. El periodista establece la ecuación populismo peronista = cuerpo enfermo, y en este sentido, afirma que "el país se enfermó gravemente" (Extra, marzo de 1976), tras "reformas agrarias del medioevo", pactos sociales, redistribución del ingreso, etc. Dice: "La Argentina está vaciada. Y cuando hay vacío de poder o el poder se recompone, o lo ocupa la izquierda nihilista o las Fuerzas Armadas. Inevitablemente". Para finalizar: "...El país es 'ingobernable'. Atormentados por nuestro 'mea culpa' y aguardando el hacha y 'el látigo' ${ }^{\prime 2}$ prometidos no escribimos más." $Y$ en el No 139 de enero de 1977, afirma que "el país no está enfermo de coyuntura. Está enfermo en profundidad". Refiriéndose a la administración pública y a las empresas en manos del Estado incita a "meter en estos primeros meses el dedo en la llaga".

Las metáforas biológicas están a la orden del día en los discursos periodísticos y militares de la época al tiempo que hay que hacer emerger una nueva Argentina sana y limpia. Así, por ejemplo, en el Proyecto Nacional del Ministerio de Planeamiento (1976), el general Díaz Bessone establece que "...las Fuerzas Armadas deben contar con la disponibilidad mental, la firme voluntad y la imaginación suficiente como para ser a la vez por todo el tiempo que sea necesario eficaz elemento de combate contra la guerrilla y el terrorismo, eficaz cirujano que extirpe el mal en todos los sectores y estratos

\footnotetext{
${ }^{1}$ El subrayado es nuestro.

${ }^{2}$ El subrayado es nuestro.
} 
sociales ${ }^{3}$, eficaz gobernante que conduzca con acierto la nave del Estado $y$, finalmente pero no al final, engendradoras y Padres de la República nueva, fuerte, unida, justa, libre, solidaria, limpia, ejemplar..." (Feierstein, 2007, p. 45).

La dictadura tuvo como objetivo destruir las bases de la sociedad populista, que implicó un régimen social de acumulación, una determinada relación entre las clases, una formación estatal e ideología hegemónica, y a través del "plan Martínez de Hoz" se propuso refundar la sociedad en términos económicos, sociales, culturales y políticos, consolidando un nuevo proyecto dominante. Ya a mediados de 1975 una delegación de empresarios liderada por Martínez de Hoz, entonces presidente del Consejo Empresario Argentino, se entrevistó en secreto con el comandante en jefe del Ejército, general Videla, para expresarle la preocupación de los grandes grupos económicos porque "se estaba impidiendo la libertad de trabajo, la producción y la productividad" (Clarín, julio de 1975) y solicitarle a las Fuerzas Armadas que aseguraran "el imperio del orden sobre todas las cosas". En lo sucesivo, las reuniones entre empresarios y militares se hicieron frecuentes.

De este modo, para el ministro de Economía, la Argentina debía responder positivamente a la proposición central del liberalismo económico: el mercado, funcionando sin interferencias, es el que asigna en forma más eficiente los recursos de una sociedad. Esta proposición es la proyección a lo económico de una filosofía política individualista, opuesta a la intromisión del Estado en la vida social más allá de estrechos límites. Consecuentemente, el liberalismo económico de Martínez de Hoz y su equipo se mantendría en una actitud de oposición estricta a todas las políticas de empleo, distribución de ingresos, seguridad social y promoción sectorial. La virtud de este planteo consistió en demostrar a las Fuerzas Armadas que el esquema políticoinstitucional que procuraban reemplazar estaba ligado estrechamente al ordenamiento económico que le daba sustento. En consecuencia, la reforma económica era una condición necesaria de la reforma política. La reducción de funciones del Estado y su conversión a "subsidiario" fue uno de los propósitos del ministro de Economía que obtuvo una importante victoria argumentativa cuando logró ensamblar la "prédica de la lucha antisubversiva con el discurso contra el Estado" (Canitrot, 1979, p. 117). El excluido social fue el nuevo homo sacer. En efecto, para el liberalismo económico el Estado solo debe satisfacer las necesidades primarias de aquellos sectores que no pueden competir en el mercado. Las personas, una vez más, son reducidas a nuda vida -vida meramente biológica.

\section{La búsqueda de consenso: el Mundial 78}

\footnotetext{
${ }^{3}$ El subrayado es nuestro.
} 
Citando a Vezzetti, Suriano afirma que debemos "mirar el rostro visible de la acción dictatorial a la luz de una trama menos visible de condiciones que la sostenían" (Suriano, 2005, p. 15).

Los apoyos manifiestos de políticos, empresarios, obispos y periodistas son irrefutables, pero el mayor impacto, y tal vez el más traumático y paradigmático, fue el respaldo a la dictadura por parte de amplios sectores de la sociedad civil a partir de dos acontecimientos tan disímiles como el fútbol y la guerra, y con implicancias ulteriores muy distintas, aunque ambos buscaron darle al gobierno la legitimidad que no tenía.

Eduardo Galeano afirma en su libro El fútbol a sol y sombra: "Participaron diez países europeos, cuatro americanos, Irán y Túnez. EL Papa de Roma envió su bendición. Al son de una marcha militar, el general Videla condecoró a Havelange en la ceremonia de la inauguración, en el estadio Monumental de Buenos Aires. A unos pasos de allí, estaba en pleno funcionamiento el Auschwitz argentino, el centro de tormento y exterminio de la Escuela de Mecánica de la Armada (ESMA). Y algunos kilómetros más allá, los aviones arrojaban a los prisioneros vivos al fondo de la mar" (Galeano, 1995, p. 97). Las víctimas del terrorismo de Estado permanecieron ocultas para la gran mayoría que concurría a ver al equipo nacional. El Mundial 78 reforzó el sistema de terror.

Evita Montonera (1978, p. 21), hace referencia a que "el Mundial de Fútbol es una inmejorable oportunidad para obligar definitivamente a Videla y sus cómplices a otorgar la apertura política y sindical. El mundo entero estará mirando a la Argentina...". Con la firma de Firmenich, el editorial concluye con "Argentina Campeón, Videla al Paredón". Pero contrariamente al diagnóstico realizado por el jefe montonero, durante el desarrollo de los partidos cientos de personas siguieron sumándose a las miles que habían sido secuestradas y desaparecidas. La dictadura puso el fútbol al servicio del terror.

Por su parte, Estrella Federal (1978, p. 3) manifiesta que las armas montoneras no se opondrán al Mundial pues "queremos que el mundo conozca nuestra lucha". Si bien Montoneros reconocía su desinserción de las bases en términos organizativos, sobre todo después de las numerosas detenciones y desapariciones de 1976 y 1977, pretendió subsanar esta deficiencia con la lucha armada.

"1978: Hacia el fin de la ofensiva enemiga", es uno de los subtítulos de este número. Allí se afirma que "el avance de las luchas de masas...ha llevado a la dictadura a una profunda crisis y al resquebrajamiento de su estrategia...Veremos este año multiplicarse las luchas sindicales y las acciones populares a las que el Ejército Montonero deberá sostener con sus armas". Mientras tanto se prepara la ofensiva de 1978.

Con la organización del Mundial, se vislumbra, como afirman Luis Scipioni et al. (2008, p. 10), un punto de inflexión. Una vez alcanzado un alto grado de disciplinamiento social, el discurso oficial tiende a estructurarse en términos positivos; de este modo, los mensajes emitidos, así como también la presentación y 
representación de acontecimientos puntuales como la llegada de la Comisión Interamericana de Derechos Humanos (1979) o la Guerra de Malvinas (1982), denotan la intención de legitimar al gobierno, ya no identificando los "defectos" del "mal social" sino afirmando y exaltando las "virtudes" del "ser argentino". Un ejemplo de esto es el slogan montado en torno a la visita de la Comisión Interamericana que aseguraba que "Los argentinos somos derechos y humanos", respondiendo a la acusación que pesaba sobre el gobierno nacional por la violación de derechos y delitos de lesa humanidad.

El concluyente informe de la CIDH, remitido al gobierno en abril de 1980, fue desfavorable, pero no agotaba -más allá del valor de su condena moral- las expectativas de los familiares de las víctimas.

\section{Malvinas como último intento de legitimación y la caída del "régimen de regímenes"}

Carta Política (1980, p. 76) argumentaba que la dictadura de 1976 era un régimen de regímenes que "aspiraba a la inmortalidad [...] al prolongar sus perspectivas más allá de una biografía [...] En 1976 el pronunciamiento militar aspiró a constituirse en régimen político al prever de qué manera sus máximas autoridades -los tres comandantes en jefe, el presidente- serían sustituidos después de un plazo [...] 1976 era el comienzo de una 'serie' institucional de fundaciones escalonadas".

Pero en 1980, más allá de lo deseado por uno de los asesores del "Proceso", comienza el período de resquebrajamiento pero ya no como "régimen de regímenes" sino como gobierno autoritario que, enredado en los efectos de su propia crisis, busca sobrevivir. Luego de la finalización del mandato de Videla (1976-1981), sus sucesores. Viola y Galtieri, no escapan al carácter de meros "ocupantes" del gobierno militar. Viola ensaya una "apertura política" obstruida por los "duros". Galtieri busca reanimar el régimen sobre la base de una gran conmoción política nacional: la invasión a las Islas Malvinas. Después de la derrota, la "estadía" de las FF.AA. en el poder político llegaba a su fin.

El fracaso del proyecto económico, el desprestigio del gobierno, la débil unidad de las FF.AA. y el despertar de la sociedad civil, son los elementos principales que rodean la aventura de Malvinas. En medio del agotamiento del régimen militar, la reconquista de las islas fue pensada como la clave de la recomposición de un sistema de dominio autoritario cimbreante y a punto de colapsar. En definitiva, la expedición militar está planteada como una forma de reconstruir el consenso perdido y de legitimar a un Estado en crisis. Las consecuencias de la derrota acentúan el desprestigio y provocan un desorden mayor en el interior del campo militar, precipitando la caída del orden autoritario hacia su resquebrajamiento, agotamiento y descomposición.

Con la operación del 2 de abril se especulaba obtener un efecto cohesivo en el orden interno: tanto en el frente militar como en el campo de la sociedad civil. El desembarco argentino conmueve al país y unifica a casi todos los sectores detrás de la 
reivindicación histórica. El régimen se lanzaba a través de una operación audaz e irresponsable, a la reconquista del consenso y al fortalecimiento de la unidad militar.

La dictadura cívico-militar y su corolario y clausura, la guerra de Malvinas, son dos caras del mismo fenómeno: despersonifica a la víctima que pasa a ser un mero cuerpo, constituyendo uno de los ejemplos más terribles de "control biopolítico". Cuando ya las fronteras no son suficientes, el conflicto se desplaza hacia el exterior buscando la legitimidad que nunca se tuvo. "Malvinas" adquirió un carácter vergonzante pero también "menor" frente a las desapariciones y torturas sistemáticas y masivas fruto de la "guerra preventiva". Así, sus combatientes quedaron sometidos a una doble marginación: son los últimos entre las víctimas de la dictadura argentina.

Los exterminios o genocidios son considerados, generalmente, una anomalía histórica, especie de retroceso de la historia o paréntesis aberrante en su marcha de progreso continua. Este quiebre regresivo aunque puntual en el proceso civilizatorio, se creyó ajeno a la condición humana. Para Hannah Arendt, contrariamente, los genocidios son su manifestación. También la guerra, en ese sentido, "es un fenómeno permanente que perdura en virtud de su plasticidad política" (Arendt, 2002, p. 67). Como afirma María José Bruña Bragado "La guerra de Malvinas no fue un anacronismo histórico -puede que sí en la 'puesta en escena' aeronaval y anfibia, un tanto obsoleta en el umbral de las guerras de los misiles-o un 'accidente' irracional, inexplicable y absurdo a finales del siglo XX. La guerra fue una decisión conscientemente tomada por sendos gobiernos que sabían que mandaban a una probable muerte a cientos de jóvenes", (Bragado, 2012, p.17). Fue una estrategia de la "biopolítica" utilizada por dos Estados, civilizados y bárbaros a la vez para perpetuarse en el poder. La Inglaterra democrática y la Argentina dictatorial se encontraban en la cuerda floja, en una encrucijada de su historia y, por ello, recurrieron a la guerra para silenciar voces opositoras, críticas y desesperanzadas.

Esta guerra estuvo atravesada por paradojas que confunden, incluso, a los sobrevivientes. Estos, muchas veces, sucumben a las versiones del nacionalismo fácil, ante la incapacidad para distanciarse o reflexionar de forma crítica sobre su propia historia. El poder los desposeyó de su identidad, de la experiencia y, a algunos, de la vida misma, pasando de ser sujetos a meros cuerpos que intuyen, pero no saben explicar las razones de su mal. La dictadura, una vez más, los despojó de la cualidad de humanos, convirtiéndolos en homo sacer. Pensemos, tan solo, en las penurias que pasaron en las Islas: la falta de abrigo, la soledad y la desprotección. Fueron nuda vida, vida desnuda, solo materia arrinconada en un pozo esperando la muerte.

\section{Conclusiones}

El terrorismo de Estado instituyó la desaparición como metodología. Wolfgang Sofsky, citado por Giorgio Agamben (2000), dice: "En el acto de matar, el poder se suprime a sí mismo. Por el contrario, al someter a sus víctimas al hambre y la 
degradación, gana tiempo, lo que le permite fundar un tercer reino entre la vida y la muerte". De eso se trata la desaparición. Convertido en un código, despojado de su nombre en vida, el desaparecido no estaba "ni vivo ni muerto" ${ }^{4}$. El desaparecido como un espectro delineó la "muerte argentina" (Careaga, 2014, Bayer, 2012).

La tanatopolítica, según Agamben (2000), no se efectiviza sobre cualquier vida. En este sentido, para que opere la muerte es necesario que intervenga una censura, un desgarro en el interior de lo social que indique que una determinada vida no merece ser vivida, que hay algo menos que humano en la propia humanidad. Para explicar tal categoría, el filósofo italiano nos presenta un nuevo concepto: la nuda vida. Nuda vida puede ser interpretado como un concepto científico o médico: la vida desprovista de toda cualificación, lo que tiene en común la vida humana con la de un caracol o una planta. Como resultado de un minucioso procedimiento biopolítico, la vida es despojada de su forma -humana-, quedando "desnuda". No se trata, en consecuencia, de la "vida calificada" o "forma de vida" que se expresa en la etimología griega de bios sino, por el contrario, de una vida impersonal e indefinida, de la pura potencia anterior a cualquier formalización y a toda división sujeto-objeto. Podría decirse que se trata de una vida "a secas" que remite a la zoé, vida sometida a un simple mantenimiento biológico.

Según Agamben, el campo de concentración nazi es la culminación de este proceso en el que la biopolítica se realiza como tanatopolítica. $Y$ así como la esencia del nacionalsocialismo tenía como fin la "reproducción biológica" de la raza aria y el aniquilamiento del judío como estereotipo de lo que "no debía ser", en la naturaleza del terrorismo de Estado argentino esa esencia se materializa en la "reproducción ideológica" del Ser Nacional y en el exterminio del subversivo como generalización de lo que "no se debía hacer" (Scipioni, et al, 2008). En ese sentido, para el "Proceso" los subversivos quedaban afuera de la categoría de "persona", como si se tratara de seres distintos a ese argentino "puro" que debía ser "protegido": "No desaparecieron personas, sino subversivos", declaró el Jefe de Policía de la Provincia de Buenos Aires durante la dictadura, general de brigada Ramón Camps (El País, 6 de febrero de 1984).

Se niegan vidas para proteger vidas...: esta es la paradoja de la "tanatopolítica". La inmunidad preserva a la comunidad, afirma Esposito (2010, p. 145). Cualquier "contagio" del cuerpo social habrá de conjurarse con la guerra preventiva. Dicha lógica se arroga la facultad de interpretar los miedos ante lo "extraño", así como la necesidad de protección ante peligros reales o aparentes.

Los dictadores del 76 evocaban a Roca para revestir con el sentido de una refundación de la Nación amenazada por una renovada forma de salvajismo, una faena de exterminio. Lo sorprendente es que el fundamento teórico, religioso, político o

\footnotetext{
4 "Le diré que frente al desaparecido en tanto esté como tal, es una incógnita, mientras sea desaparecido no puede tener tratamiento especial, porque no tiene entidad. No está muerto ni vivo...está desaparecido". (Declaraciones de Videla en conferencia de prensa dada el 14/12/ 1979).
} 
moral que sustenta esas prácticas tanáticas se elabora precisamente invocando la preservación de la vida -o de la moral- (Díaz, 2010). La noción de biopoder -la vida biológicamente considerada, la nuda vida- "en su doble faz, como poder sobre la vida y como poder sobre la muerte", se muestra con toda crudeza en la acción del Estado terrorista argentino, destinado a intervenir, una vez más, frente al caos y los fantasmas de la anarquía en un proyecto de salvación nacional.

Para que existiera un ser argentino puro, portador de los valores occidentales y cristianos, se necesitó construir una subversión apátrida, peligrosa, atea, bárbara. Para que hubiera un Nosotros superior, se necesitó construir un Otro inferior.

Si en el nazismo ese Otro era el gitano, el homosexual y sobre todo el judío, Mariano Grondona en 1977, en su revista escribía el artículo "Los judíos" en el cual señalaba que en un país en formación como la Argentina era necesaria una homogeneidad étnica y religiosa para que se pudiera construir la nación. Bajo este radical punto de vista, como bien dice Feierstein (2006, p. 387), los judíos debían exiliarse o convertirse al catolicismo.

El golpe abrió las puertas a un cambio drástico en la distribución del poder social. El "empate hegemónico" (Portantiero, 1977) que regía desde los años 50 fue derribado con violencia. En su lugar, se sentaron las bases para el empobrecimiento de sectores medios y populares en beneficio de los grandes grupos económicos. No solo se profundizaron las asimetrías. Las expectativas con que habían crecido social y culturalmente los argentinos se hicieron pedazos.

Para que haya cuerpos productivos tiene que haber cuerpos sometidos. Todo sometimiento económico conlleva un sometimiento político que lo posibilita. Al analizar la historia reciente, queda a la vista que la implantación del neoliberalismo económico solo fue posible mediante la dominación de esos cuerpos. Llegados a este punto es necesario resaltar las marcas que el poder dejó no solo sobre los cuerpos de los detenidos-desaparecidos, sino también sobre la sociedad en su conjunto. El dominio ejercido sobre esos cuerpos y la violencia del poder disciplinario no son directos. La "docilización" es mucho más sutil. Con los dispositivos disciplinarios funcionando mediante castigos y recompensas, se inmovilizó a buena parte de la sociedad. Ese es el gran éxito que consiguió la dictadura: someter a la sociedad por el miedo. El vigilar resultó tan efectivo como el castigar.

El golpe de Estado precedió al Estado terrorista. El "estado de excepción" se legitimó por una percepción de amenaza al estado de derecho o a la Constitución Nacional. Ese Estado operó en un espacio vacío de derecho, en el cual todas las determinaciones jurídicas fueron desactivadas. En este sentido, "es ese momento del derecho en el que se suspende el derecho, precisamente para garantizar su continuidad e inclusive su existencia. O también: la forma legal de aquello que no puede tener forma legal, porque es incluido en la legalidad a través de su exclusión", afirma Agamben (2005, p. 24). El golpe se justificó en un supuesto "vacío de poder", responsabilizándose por ello 
a las "rígidas estructuras políticas y económicas anacrónicas". Dice Pilar Calveiro (2013, p. 27): "fueron los militares los primeros en decretar el agotamiento democrático reiterando el mecanismo de desaparecer lo inmanejable. Ante la imposibilidad de desaparecer al peronismo, que reaparecía en las alianzas políticas y en la lucha sindical, se optaba por desaparecer la democracia e incluso la política".

En Carta Política y Extra, sus directores, en tanto "consejeros del Príncipe", buscaron desde aristas diferenciadas influir en la cúpula militar. A la guerra no convencional "preventiva" en términos biopolíticos- le debía suceder una etapa de estabilidad a partir de una convergencia "definitiva" entre civiles y militares. La supervivencia de la "Nación" misma estaba en juego. Por ello, hubo una voluntad expresa de destruir la identidad de los sectores populares que se expresaba en el peronismo. Todo vestigio de populismo debía ser desterrado de la faz de la Argentina (Basualdo, 2006, p. 30). Para Grondona y Neustadt, las FF.AA. no operaban representando intereses sectoriales, sino que eran "los fundadores" de una Argentina que el accionar de la subversión y de los populistas habían desvirtuado.

Por su parte, Evita Montonera y Estrella Federal insistían en que se debía recorrer un largo y doloroso camino, aunque el costo fuera inmenso; pero, en definitiva, el enemigo era débil y la fuerza del pueblo organizado poderosa. También los militantes de esta organización defendían una idea de Nación, como dijimos en párrafos anteriores. En efecto, para la JP y sus organizaciones "el ser nacional se expresa en una comunidad establecida en un ámbito geográfico y económico, jurídicamente organizada en nación, unida por la misma lengua, un pasado común, instituciones históricas, creencias y tradiciones también comunes conservadas en la memoria del pueblo, y amuralladas, tales representaciones colectivas, en sus clases no ligadas al imperialismo, en una actitud de defensa ante embates internos y externos, que en tanto disposición revolucionaria de las masas oprimidas, se manifiesta como conciencia antiimperialista, como voluntad de destino", tal como lo expresa la revista El Descamisado de abril de 1973 (p. 9), transcribiendo la definición que Hernández Arregui da en su obra ¿Qué es el ser nacional?.

El terrorismo de Estado es un ejercicio del poder estatal, afirma Ernesto Garzón Valdés (1989, pp. 35-36), que adquiere las siguientes notas: 1) afirma la existencia de una guerra contra un enemigo infiltrado en todos los niveles de la sociedad, que suele actuar como agente de una confabulación internacional: 2) delimita en forma imprecisa los hechos punibles a la vez que elimina el proceso judicial; 3) impone clandestinamente medidas de sanción estatal prohibidas por el orden jurídico oficialmente proclamado -torturas y homicidios, entre otras-, y 4) aplica medidas violentas de privación de la libertad, la propiedad o la vida, con prescindencia, en muchos casos, de la identidad del destinatario de las mismas y de los actos u omisiones de los que puedan ser responsables. La aplicación de la violencia a víctimas inocentes contribuye a reforzar la "eficacia" del terror. 
Asimismo, la lucha contra el "subversivo" permitió confundir excepción con normalidad, ante el "convencimiento" de que peligraba la supervivencia misma de la Nación argentina.

En la medida en que se trataba de "aniquilar" a las organizaciones guerrilleras, el objetivo fue cumplido a costa de imponer un proceso de criminalización del Estado. La razón de que un Estado totalitario recurra al método de la "desaparición de personas" se debe a su efecto de supresión de todo derecho: al no existir cuerpo del delito se garantiza la impunidad: el desconocimiento impide a los familiares y a la sociedad realizar acciones legales, a la vez que infunde terror en las víctimas y en la sociedad y mantiene separados a los ciudadanos en su accionar frente al Estado. La desaparición es lo que vuelve al opositor un homo sacer por excelencia.

Roberto Alemann, propietario y director del Argentinisches Tageblat, y ministro de Economía bajo el gobierno de Galtieri, editorializaba algunos meses antes del golpe (agosto de 1974, p. 3): "se llega a la conclusión de que el Gobierno podría acelerar y facilitar ampliamente su victoria actuando contra la cumbre visible, de ser posible al amparo de la noche y la niebla $a^{5}$ y calladamente, sin echar las campanas al vuelo...", con lo cual se aludía al Decreto Nacht und Nebel (Noche y Niebla) de Hitler del 7 de diciembre de 1941, referido a la desaparición de personas.

El terrorismo de Estado requiere, asimismo, de una organización ideológica cuya base es un dogma, una idea que vale como pauta absoluta, incuestionable, y que sirve de excusa o justificación para la destrucción de todo aquello que se oponga a ella. Este papel lo cumplía la Doctrina de Seguridad Nacional, aunque en el caso de la dictadura del 76, esta deja de circunscribirse a las vanguardias armadas. De ahora en más, la amplitud de su aplicación tendrá una vastedad sin precedentes, aun bajo otras dictaduras militares (Basualdo, 2006, p. 34).

"La idea de una violenta restitución de la integridad de la Nación, que pretendía suprimir las manifestaciones del antagonismo, negaba la existencia misma del conflicto social y político. Se transmitía, así, una visión que es propia del totalitarismo: la operación imposible de la reincorporación de las diferencias en un cuerpo político unificado, una unidad imaginaria que es previa a las instituciones y a las leyes. Sólo la fugaz transformación de la relación con la sociedad producida durante la guerra de las Malvinas produjo un estado de fusión patriótica que ilusionó a unos cuantos civiles y militares..." (Vezzetti, 2008, p. 57).

La categoría de "ser nacional"/"ser argentino" está estrechamente vinculada a la de identidad esencial que afirma que cualquier ente -persona, cosa, grupo- es idéntico a sí mismo. Es decir "es lo que es y no puede ser de otra manera". No existe la posibilidad de cambio pues entraría en colisión con sus componentes esenciales.

\footnotetext{
${ }^{5}$ El subrayado es nuestro.
} 
Una identidad esencial, trátese en este caso de la nacional, la llamada "argentinidad", considera a lo "otro" como extraño a lo propio y, por ende, peligroso pues puede conspirar contra los rasgos "naturales/esenciales" que hacen a una "argentinidad" auténtica. Pero la identidad es una construcción de sentido, pertenece a una época, es cambiante, y el poder tiene mucho que ver con esta construcción.

La aceptación de los valores del "ser nacional" homogéneo y resistente a cualquier tipo de cambio, estuvo marcada por la inoculación del miedo; el terrorismo de Estado penetró todos los ámbitos sociales. De manera paralela al funcionamiento de los instrumentos coercitivos, la "política del miedo" se ejercía como una violencia simbólica que paralizaba a aquellos sectores sociales no cooptados a la vez que se recuperaban representaciones conservadoras que habían sido puestas en tela de juicio a partir de los 60. Sobre esta base, los métodos propagandísticos tuvieron efectos similares a los de la Alemania nazi, es decir, la recepción acrítica de los mensajes y la consecuente conducta social en los términos planificados por la Junta Militar. Como bien se manifiesta en "Los rostros del biopoder" (2008, p. 3), "existe un punto evidente de continuidad semántica en ambos Estados en relación a la apología de los valores occidentales clásicos; aparece una muletilla a la que se acudía mucho por entonces, 'la defensa de la civilización occidental y cristiana', casi una réplica del paradigmático slogan 'por la defensa de la civilización cristiana' creado por Joseph Goebbels durante el nazismo".

Apenas terminada la guerra de Malvinas, comenzaron a descubrirse las huellas más visibles de la represión: enterramientos, lugares de detención y tortura, testimonios de sobrevivientes.

Por su parte, el "legado" económico deja a la sociedad y a las autoridades entrantes un endeudamiento masivo, un aparato productivo deteriorado y un pronunciado proceso de desindustrialización.

Deseamos terminar este artículo con un pequeño comentario de la reflexión de Roberto Esposito (2005) acerca de la comunidad. Esposito distingue el pensamiento de la comunidad de las filosofías de la representación, las cuales han asociado la seguridad de la vida y su preservación ante la muerte junto al "apaciguamiento" del miedo que esta suscita, en las figuras de la propiedad y del tener -poder, prestigio, dinero y honores. Estas soluciones han degradado, mutilado y provocado más miedo y muertes que paz y beneficios a la vida de los hombres.

Lo que nos vincula en la comunidad es la falta, la finitud, la ausencia de completitud; no el pertenecer, sino el no-ser todo.

Este carácter de incompleto es a la vez deuda y don. El don, la donación de la vida y de la muerte en común, otorgan sentido a la vida que se sabe finita. Deuda impagable y don que no espera retribución, porque se da lo que no se tiene, no hay cálculo posible. Compartir esa carga nos liga en lo común y nos hace comunidad de nada y de nadie: no hay propiedad. 
No hay enemigo, extranjero, Otro. El conflicto presente, como acto o como potencia, como guerra declarada o como amenaza, anida en la comunidad para inmunizar aquello que se considera impuro, para neutralizar o combatir el "afuera". Por ello, la lógica biunívoca amigo-enemigo no nos permite comprender la complejidad que encierra la comunidad.

\section{Referencias bibliográficas}

- Agamben, Giorgio, (2003). Homo sacer. Valencia: Pre-Textos.

Agamben, G. (2005). Estado de excepción. Buenos Aires: Adriana Hidalgo Editora.

Agamben, G. (2000). Lo que queda de Auschwitz. El archivo y el testigo. Homo sacer III. Valencia: Pre-Textos.

- Arendt, Hannah (1989). Nach Auschwitz. Essays \& Kommentare I. Berlin: ed. Eike Geisel y Klaus Bittermann,

Arendt, H. (2002). Los orígenes del totalitarismo. Madrid: Gallimard.

- Basualdo, Eduardo M. (2006). Sistema político y modelo de acumulación en la Argentina. Buenos Aires: UNQUI.

- Bayer, Osvaldo (2012). Palabras en Página 12, 24 de marzo de 2012.

- Bragado, María José Bruña (2012). Ruinas del imaginario nacional argentino: contar Malvinas. Salamanca: Universidad de Salamanca, (paper).

- Calveiro, Pilar (2013). Política y/o violencia. Buenos Aires: Siglo Veintiuno Editores.

- Canitrot, Adolfo (1979). La disciplina como objetivo de la política económica. Un ensayo sobre el programa del gobierno argentino desde 1976, 2, 6. Buenos Aires: Estudios CEDES.

- Careaga, Ana M. (2014). "Nadie sabía lo que todos sabían", Página 12, 25 de setiembre de 2014.

- Díaz, Esther (2010). "Investigaciones multidisciplinarias y transferencia. La biopolítica y las tecnologías del poder-saber". Buenos Aires: Universidad Nacional de Lanús, (paper).

- Esposito, Roberto (2004). Bíos. Biopolítica y filosofía. Madrid: Amorrortu.

Esposito, R. (2005). Communitas. Origen y destino de la comunidad. Buenos Aires: Amorrortu.

Esposito, R. (2010). Inmunitas. Protección y negación de la vida. Buenos Aires: Amorrortu.

- Feierstein, Ricardo (2006). Historia de los judíos argentinos. Buenos Aires, Galerna.

Feierstein, R. (2007). "Sobre el rol del derecho en la construcción de la memoria. La calificación de los hechos y sus efectos de memoria", Revista Ciencias Sociales, 77, 15-17. Buenos Aires: UBA.

- Foucault, M. (1996). Genealogía del racismo. Buenos Aires: Editorial Altamira.

- Galeano, E. (1995). El fútbol a sol y sombra. Buenos Aires: Siglo XXI Editores. 
• Garzón Valdés, Ernesto (1989). "El terrorismo de Estado", Revista de Estudios Políticos, 65, pp. 35-40. Madrid: Centro de Estudios Políticos y Constitucionales.

- Micieli, Cristina (dir.), Pelazas Myriam (co-dir.) y Dipierri, Pablo; Mira, María Eva y Picotti, Gustavo C. (investigadores) (2012). Dar la vida/quitar la vida. El peronismo en los 70 a través de El Descamisado y El Caudillo. Buenos Aires: Editorial La Parte Maldita. 2012.

- Portantiero, J.C. (1977). "Economía y política en la crisis argentina: 1958-1973", Revista Mexicana de Sociología, 2, México.

'Quiroga, Hugo (2004). El tiempo del "Proceso". Conflictos y coincidencias entre políticos y militares 1976-1983. Santa Fe: Homo Sapiens.

- Reato, Ceferino (2012). Disposición Final. La confesión de Videla sobre los desaparecidos. Buenos Aires: Sudamericana.

- Scipioni, Luis; Salazar, Mayra; Rivero Leguizamón, Juan Pablo (2008). "Los rostros del biopoder". Jornadas de Cuerpo y Cultura. Universidad Nacional de La Plata, 17, (paper).

- Suriano, Juan (2005). Nueva historia argentina. Buenos Aires: Sudamericana.

- Vezzetti, Hugo (2008). Pasado y presente. Guerra, dictadura y sociedad en la Argentina. Buenos Aires: Siglo XXI Editores.

\section{Referencias electrónicas}

Discurso dirigido al Pueblo Argentino el día 24 de mayo de 1976 por el Excelentísimo Señor Presidente de la Nación, teniente general Jorge Rafael Videla, refiriéndose al Proceso de Reorganización Nacional, al cumplirse dos meses de iniciado el mismo. ${ }^{6}$ Mensaje pronunciado el 17 de abril de 1976 por el Excelentísimo Señor Presidente de la Nación, teniente general Jorge Rafael Videla, y dirigido al Pueblo de la República con motivo de la celebración de la Semana Santa y la Pascua de Resurrección ${ }^{7}$.

Discurso pronunciado el día 30 de marzo de 1976 por el Excelentísimo Señor Presidente de la Nación, teniente general Jorge Rafael Videla, al asumir la Primera Magistratura de la República Argentina. ${ }^{8}$

Instrucción de lucha contra elementos subversivos. Conocido como Documento Reservado del Ejército Argentino (23/8/76). ${ }^{9}$

\footnotetext{
${ }^{6}$ En www.ruinasdigitales.com.ar

${ }^{7}$ Idem.

${ }^{8}$ Idem.

${ }^{9}$ Idem.
} 
De Prácticas y discursos/ Universidad Nacional del Nordeste/ Centro de Estudios Sociales

\section{Revistas}

Grondona, Mariano, Carta Política (números 1976-1982).

Neustadt, Bernardo, Extra (números 1974-1983).

Evita Montonera (números 1976-1979). ${ }^{10}$

Estrella Federal (4 números 1977-1978). ${ }^{11}$

\footnotetext{
${ }^{10}$ Idem

${ }^{11}$ Idem.
} 